\title{
UTILIZAÇÃO DE CARACTERÍSTICAS MICROBIOLÓGICAS NA AVALIAÇÃO DA DEGRADAÇÃO OU RECUPERAÇÃO DE UMA ÁREA SOB MINERAÇÃO DE FERRO(1)
}

\author{
A. V.TRINDADE ${ }^{(2)}$, P. H. GRAZZIOTTI (3) \& M. R. TÓTOLA ${ }^{(4)}$
}

\begin{abstract}
RESUMO
O estado de degradação e, ou, recuperação de diferentes sítios de uma área de mineração de ferro no município de Mariana (MG) foi avaliado pela atividade microbiana, número de esporos de fungos micorrízicos arbusculares (FMA) e população total de fungos e bactérias. Os substratos presentes em cada sítio, caracterizados como Rejeito de flotação (Rj), Solo superficial (SS), Subsolo (Ss), Subsolo com vegetação (SsV), Área em revegetação (AR ) e Mata secundária (MS), foram amostrados na profundidade de $10-25 \mathrm{~cm}$, retirando-se uma amostra composta, formada por oito amostras simples. A ati vidade microbiana foi avaliada pela evolução de $\mathrm{CO}_{2}$ em amostras ao natural e com adição de sacarose ou sacarose + uréia. Fez-se também a determinação de características químicas e teor de umidade. A colonização do substrato SsV por gramíneas e plantas de candeia (Vanill osmopsis erythropappa Schult. Bip.) foi acompanhada pelo número de esporos de FMA, teor de carbono orgânico e atividade microbiana. Os esporos de FMA só foram observados em áreas com vegetação. 0 armazenamento da camada superficial de solo (sítio SS) reduziu os teores de carbono orgânico, nitrogênio total, número de esporos de FMA e atividade microbiana. Nos substratos resultantes da atividade mineradora, houve necessidade do fornecimento conjunto de carbono e nitrogênio para estimular a atividade microbiana. As características microbiológicas avaliadas apresentaram valores maiores no sítio de mata secundária do que nos demais amostrados, indicando que aqueles em recuperação não possuíam o mesmo equilíbrio biológico. As avaliações microbiológicas do solo foram capazes de distinguir os estados de perturbação ou recuperação das diferentes áreas estudadas.
\end{abstract}

Termos de indexação: atividade microbiana, fungos micorrízicos, respiração, bactérias.

\footnotetext{
(1) Trabalho apresentado no XXV Congresso Brasileiro de Ciência do Solo, em 23-28 de julho de 1995. Recebido para publicação em março de 1998 e aprovado em maio de 2000. Parcialmente financiado pelo CNPq.

(2) Pesquisador, Embrapa Mandioca e Fruticultura, Rua Embrapa s/n, Caixa Postal 007, CEP: 44380-000 Cruz das Almas (BA). E-mail: aldo@cnpmf.embrapa.br.

(3) Técnico Especializado III, Embrapa Recursos Genéticos, SAIN Parque Rural, Av. W5 Norte, CEP: $70770-900$ Brasília (DF). E-mail: grazziott@cenargen.embrapa.br

(4) Professor do Departamento de Microbiologia da Universidade Federal de Viçosa (UFV), CEP 36570-001 Viçosa (MG).
} 


\title{
SUMMARY: USE OF MICROBIOLOGICAL PROPERTIES ON THE EVALUATION OF DEGRADATION/RECLAMATION OF AN AREA UNDER IRON MINING
}

\begin{abstract}
Different sites of an iron mining from Mariana, Minas Gerais, Brazil, were evaluated for determining the degree of their degradation or reclamation, using microbial activity of soil, spore numbers of arbuscular mycorrhizal fungi (AMF) and total count of fungi and bacteria. Each sitecontained a substratecharacterized as flotation refuse $(R j)$, Soil without vegetation (SS), Subsoil (Ss), Subsoil with vegetation (SsV), site under recuperation (AR) and forest (MS), and was sampled at 10-25 cm. Establishment of grasses and "candeia" (Vanillosmopsis erythropappa Schult. Bip.) plants in subsoil samples increased spore number of AMF, organic carbon content and microbial activity obtained by adition of sucrose and sucrose + urea. Spores of AMF were detected in sites with plant growth, only. Topsoil storagereduced organic carbon content, total nitrogen, sporenumber of AMF and microbial activity. In thematerial/ substrates generated by iron mining, mi crobial activity responded only after carbon and nitrogen adition. Microbiological parameters evaluated weregreater on the (undisturbed) forest site than on the other soils or substrates, indicating that the sites under redamation werenot under thesamebiol ogical equilibrium. Soil microbiol ogical evaluation could distinguish the degree of degradation or reclamation of the different sites studied.
\end{abstract}

Index terms: microbial activity, mycorrhizal fungi, respiration, bacteria.

\section{INTRODUÇÃO}

No Brasil, desde o final da década de 80 , as empresas mineradoras que geram impacto sobre o meio ambiente são obrigadas, por lei, a criar programas de recomposição florística das áreas afetadas. A revegetação dessas áreas éessencial para alcançar um desenvolvimento sustentável e deve acontecer desde o estabelecimento das atividades extrativistas até um longo período após o encerramento destas (Motta Neto et al., 1994).

A atividade de mineração causa, de início, uma degradação pontual na área de atuaçã̃o, pela retirada da vegetação nativa, da camada superficial de soloe da geração de rejeito. Dessa atividade, resultam substratos que podem apresentar características inadequadas ao desenvolvimento vegetal, como, por exemplo: baixa taxa de infiltração de água, desuniformidade das superfícies, baixa aeração, presença de metais pesados, deficiência de nutrientes, alta salinidade evalores extremos de pH (Lamont, 1978; F ox, 1984). Tais alterações causam queda na produtividade edegradação do ecossistema (Siqueira et al., 1994). A recuperação dessas áreas vai depender, dentre outros fatores, de uma mi crobiota ativa, já que esteéum componente chave na manutenção de um ecossistema em equilíbrio, em virtude de sua participação na ciclagem de nutrientes e de mudanças físico-químicas necessárias para a formação deuma camada propícia ao enraizamento e crescimento das plantas. A população microbiana do solo exerce papel fundamental para o perfeito funcionamento do sistema sol o-planta, especial mente nos ecossistemas naturais onde a fertilidade do solo depende, quase que inteiramente, dos processos microbianos (Siqueira et al., 1994).

O efeito danoso da ação do homem no ecossistema, tal como a atividade demineração de carvão sobre a comunidade mi crobiana do solo, tem sido documentado (Rives et al., 1980; Stroo \& J encks, 1982; Williamson \& J ohnson, 1990). Williamson \& J ohnson (1990) observaram que a maioria das bactérias presentes na camada superficial de solo, estocada em montes, mostrava-se inviável equea biomassa fúngica viável foi menor do que aquela de solos não perturbados.

Sendo assim, características mi crobiológicas, tais como: bi omassa, atividade (respi ração, ATP, atividade enzimática etc.), contagem direta e indireta da população microbiana, quantificação de mi crorganismos específicos (fungos micorrízicos, bactérias fixadoras de $\mathrm{N}_{2}$ etc.), podem ser usadas nas avaliações de estado de equilíbrio de áreas submetidas a diferentes ações antrópicas.

Mediante uso de Análise de Componentes Principais, Bentham et al. (1992) observaram que indíces microbiológicos (atividade da deidrogenase do solo, ATP e ergosterol) possi bi litaram a distinção entre habitat, quanto ao estado de recuperação, o que não foi possível com o uso de características físico-químicas isoladas.

O obj etivo deste trabal ho foi avaliar o estado de degradaçãoe, ou, de recuperação desítios de uma área de mineração de ferro, com base em características microbiológicas. 


\section{MATE RIAL E MÉTODOS}

O município de Mariana, MG, situa-se em área dominada por depósitos naturais de minério deferro. E scol heu-se uma das mineradoras da região para se fazer uma avaliação do impacto gerado pela atividade extrativista. Foram amostrados diferentes sol os ou substratos resultantes das operações de lavra, tendo como controle uma área adjacente não perturbada, visando à avaliação da atividademicrobiana, número de esporos de fungos micorrízicos arbusculares (FMA) e população total defungos e bactérias. Seguese a descrição de cada material amostrado:

Rejeito de flotação (Rj) - Substrato gerado pel o processo físico-químico de extração de ferro, com granulometria arenosa, decomposição domi nada por quartzo, mas que continha el evados teores de ferro. É depositado em piscinas e constituiu-se de depósito recente, sem presença de vegetação.

Solo Superficial (SS) - Camada de solo retirada da área de lavra (mina), depositada ao ar livre, para posterior recomposição da área. Este material apresentava material orgânico aparente, como pedaços de caule e raízes.

Subsolo (Ss) - Material com baixoteor deFeque não é utilizado para extração do minério, sendo caracterizado como I tabirito Anfibolítico, na forma de depósito ao ar livre sem presença de vegetação ou material de natureza orgânica, visível.

Subsolo com Vegetação (SsV) - Depósito antigo do mesmo material de origem que o Ss e que foi deixado ao ar livre na base de uma encosta, apresentando vegetação nativa (gramíneas, candeia, entre outras espécies).

Área em Revegetação (AR) - Área que foi terraplenada e que recebeu material do tipo SS. I nicialmente, foi colonizada por vegetação rasteira nativa; posteriormente, foi plantada com espécies nativas em espaçamento $2 \times 2 \mathrm{~m}$.

Mata Secundária (MS) - Área não perturbada, com domi nância deembaúba (Cecropia pachystachya Trecul) e muitas espécies rasteiras (subosque).

Inicialmente, fez-se a limpeza do local de coleta (para retirada de vegetação, quando existente), retirando-se amostras ao acaso, com enxada e pá reta, na profundidade de $10-25 \mathrm{~cm}$. De cada sítio, foram tomadas oito amostras simples de, aproximadamente, $1 \mathrm{~kg}$, que, juntas, formaram uma amostra composta. Estas foram col ocadas em sacos plásticos com a umidade natural e deixadas em câmara fria $\left(18^{\circ} \mathrm{C}\right)$, por $48 \mathrm{~h}$, quando se fez 0 processamento e foram iniciadas as avaliações.

No preparo, as amostras foram, inicialmente, passadas em peneira de malha de $4 \mathrm{~mm}$ deabertura, para homogeneização. De cada amostra, foram tomadas subamostras de $100 \mathrm{~g}$ para realização do ensaio de atividade microbiana, medida pela respiração. Ao mesmo tempo, tomaram-se amostras de 100 g para determinação deumidade, no momento do início da incubação, para posterior correção dos val ores de respiração obtidos. Os valores deumidade foram: $\mathrm{Rj}=14$ dag kg-1; SS = 16,7 dag kg-1; Ss =

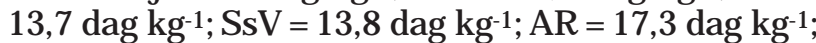
$\mathrm{MS}=30,5$ dag kg-1.

No ensaio de respiração, além do material nas suas condições originais, foram introduzidos dois tratamentos: fornecimento de sacarose $\left(1,2 \mathrm{dag} \mathrm{kg}^{-1}\right)$ e sacarose $\left(1,2{\left.\text { dag } \mathrm{kg}^{-1}\right)}^{-1}\right.$ + uréia $\left(0,06 \mathrm{dag} \mathrm{kg}^{-1}\right)$, considerando-se o sol o com sua umi dade natural. O experimento foi realizado com duas repetições. Utilizou-se um sistema de fluxo contínuo com as amostras depositadas em erlenmeyer de $125 \mathrm{~m} \mathrm{~L}^{-1}$, com um tubo para entrada de ar isento de $\mathrm{CO}_{2}$ [após passagem em colunas de $\mathrm{CaCl}_{2}, \mathrm{NaOH}$ e solução de $\mathrm{Ba}(\mathrm{OH})_{2}$ ] e outro de saída do ar respirado, o qual era col etado em solução de $\mathrm{NaOH}$ e, posteriormente, titulado com HCl 0,5 mol L-1, usando-sefenol ftaleína (1 dag L-1) como indicador. A determinação foi feita durante $159 \mathrm{~h}$, col etando-se amostras em intervalos variáveis, mas nunca superiores a 24 ou inferiores a 7,5 h. No total, foram feitas 10 tomadas de dados. Após a titulação, fez-se o cál culo do teor de $\mathrm{CO}_{2}$ em $\mathrm{cmol} \mathrm{kg}^{-1}$ de solo seco.

$\mathrm{Na}$ contagem do número de unidades formadoras de colônias (UFC) de bactérias e fungos, utilizou-se o método da inoculação no sistema "pour plate" de suspensões diluídas de solo em mei oágar nutriente, para bactérias (Wollum II, 1982) com adição de $50 \mathrm{mg} \mathrm{L}^{-1}$ de ciclohexamida e meio Martin para fungos, com adição de $30 \mathrm{mg} \mathrm{L}^{-1}$ de estreptomicina (Wollum II , 1982). O plaqueamento foi feito por meio de diluições 10-1, 10-2, 10-3, 10-4 e 10-5. As placas foram acondicionadas em estufa à temperatura de $24-29^{\circ} \mathrm{C}$, avaliando-se o número de UFC aos três dias, para bactérias, e aos sete dias, para fungos.

Para avaliar o número de esporos de FMA, tomaram-se duas subamostras de 20 g eextração pela técnica de peneiramento úmido e centrifugação em sol ução de sacar ose (Gerdemann \& Nicolson, 1963). Fez-se contagem total, utilizando-se placa circular concêntrica.

De cada amostra, retiraram-sesubamostras para determinação de $\mathrm{pH}$ e teores de matéria orgânica e nitrogênio total (EMBRAPA, 1979).

\section{RESULTADOS E DISCUSSÃO}

Em comparação ao Ss, a col onização do substrato SsV por gramíneas e candeia foi acompanhada de maior número de esporos de fungos micorrízicos arbusculares (FMA) (Figura 1), teor de carbono 
orgânico(Quadro 1) eatividademicrobiana obtida pela adição de sacarose e sacarose + uréia (Figura 2). A importância da presença da cobertura vegetal sobre a microbiota havia sido observada em um trabalho na região sul do Brasil, a respeito de diferentes tipos de manejo do sol o sobre a população mi crobiana. Os resultados mostraram um decréscimo de $65 \%$ na biomassa microbiana, quando se retirou a vegetação de um campo nativo, apresentando os menores val ores de biomassa e atividade microbiana, quando comparados aos diferentes sistemas de cultivos, consorciados ou não, além do campo nativo (Cattelan \& Vidor, 1990a). A população defungos, actinomicetos, solubilizadores de fosfato e, principalmente, a de bactérias foi afetada pela retirada da cobertura vegetal nesteecossistema (Cattelan \& Vidor, 1990b).

Dentre os sítios estudados, esporos de FMA só ocorreram em áreas com presença de vegetação ou raízes (SS, SsV, AR e MS), devido à condição de simbionte obrigatório destes fungos, os quais dependem da planta hospedeira para obter carbono e, conseqüentemente, completar o seu cicl o de vida. Dentre esses sítios, onúmero de esporos de FMA foi maior na área de mata secundária (não-perturbada), o que pode ser considerado um indicativo de que os substratos em recomposição ou recuperação não atingiram o equilíbrio natural antes presente. A quantificação de fungos e bactérias (UFC/g de solo seco, Quadro 1) mostrou maiores populações desses microrganismos na área de mata secundária, o que corrobora os dados de esporos de FMA. No rejeito, não foi detectada a presença de fungos, o que pode ser resultado do elevado valor de $\mathrm{pH}$ apresentado por aquele substrato.

Os substratos SS e AR, que correspondem à camada superficial de solo, apresentaram teores de

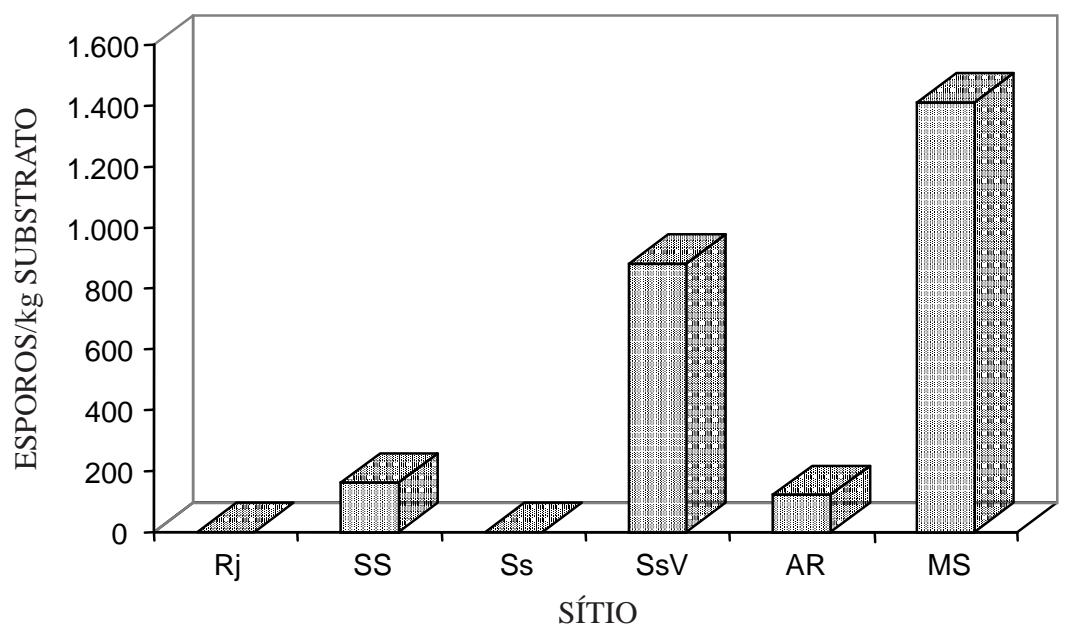

Figura 1. Número de esporos de fungos micorrízicos arbusculares em diferentes sítios em área de mineração de ferro (Rejeito de flotação (Rj); Solo Superficial (SS); Subsolo (Ss); Subsolo com Vegetação (SsV); Área em Revegetação (AR); Mata Secundária (MS).

Quadro 1. Características químicas e biológicas de diferentes sítios em área de mineração

\begin{tabular}{|c|c|c|c|c|c|c|}
\hline Substrato(1) & $\mathrm{pH} \mathrm{H} \mathrm{H}_{2} \mathrm{O}(2,5: 1)$ & C-orgânico & $\mathrm{N}$-total & Relação C/N & Fungo $\left(x 10^{3}\right)$ & Bactéria (x 108) \\
\hline & & \multicolumn{2}{|c|}{$\mathrm{g} \mathrm{kg}^{-1}$} & & \multicolumn{2}{|c|}{ _ UFC/g de solo seco(2) _ } \\
\hline $\mathrm{Rj}$ & 8,39 & 2,5 & 0,3 & 8,3 & $n d^{(3)}$ & 0,2 \\
\hline SS & 5,16 & 11,0 & 1,4 & 7,9 & 43,0 & 1,7 \\
\hline Ss & 5,52 & 1,8 & 0,5 & 3,6 & 2,7 & 1,5 \\
\hline SsV & 5,70 & 5,4 & 0,5 & 10,8 & 20,0 & 9,0 \\
\hline$A R$ & 5,25 & 9,7 & 0,9 & 10,8 & 9,7 & 0,01 \\
\hline MS & 4,59 & 61,0 & 4,1 & 14,9 & 97,0 & 121 \\
\hline
\end{tabular}

(1) Rejeito de flotação (Rj); Solo Superficial (SS); Subsolo (Ss); Subsolo com Vegetação (SsV); Área em Revegetação (AR); Mata Secundária (MS). (2) UFC - unidade formadora de colônia. (3) Não detectado. 
carbono orgânico e nitrogênio total muito abaixo dos valores encontrados na área de mata secundária. I sso pode ser reflexo do período de armazenamento da camada superficial de solo, que deve ter propiciado a decomposição de carbono orgânico e perda por lixiviação do nitrogênio após sua mineralização, sem entrada de matéria orgânica. A ocorrência de pequeno número de esporos de FMA nas amostras deSS eAR, quando comparadas à MS, indica que o processo de armazenamento da camada superficial de solo não conservou as condições naturais ocorrentes na área. No entanto, a adição da camada de solo como veículo de sementes e de microrganismos tem sido adotada, em face de sua importância para o estabel ecimento da vegetação em áreas mineradas (Riches \& J ones, 1979). Barth (1989) considerou que a maior importância desse material nos programas de recuperação talvez se deva à presença de microrganismos benéficos. No entanto, o manejo queé dadoa esse material durante a estocagem, por períodos longos, pode reduzir sua eficiência como fonte de inóculo de mi crorganismos (Rives et al., 1980), o que foi confirmado pelos resultados obtidos neste trabalho.

A atividade microbiana, medida pela emissão de $\mathrm{CO}_{2}$, foi baixa nas amostras em condição natural (sem adição de carbono ou nitrogênio) em todas as áreas, embora tenha apresentado valores maiores na mata secundária (MS) eno rejeito (Rj) (Figura 2). $\mathrm{O}$ incremento de $\mathrm{CO}_{2}$ em função do tempo também foi maior nesses dois sítios, como demonstram os coeficientes lineares das equações ajustadas aos dados. Para osítio MS, a maior atividade mi crobiana está relacionada com a maior população de microrganismos (fungos e bactérias) observada naquela área (Quadro 1). No rejeito, a atividade deve-se basicamenteà população de bactérias já que não foi detectado crescimento de fungos nessa amostra. Tendo em vista que o rejeito estava sujeito à condição de anaerobiose, devido ao excesso de umidade, é possível que o método utilizado para quantificação da população de microrganismos (bactérias efungos) não tenha sido capaz de detectar alguma população específica existente naquela condição. Por outro lado, a umidade utilizada na avaliação da respiração microbiana para o rejeito foi menor do que aquela ocorrente na área onde a amostra foi coletada; sendo assim, a eliminação ou redução da condição de anaerobiose pode ter provocado maior atividade em decorrência da busca de um novo equilíbrio pela população microbiana.

A menor atividade microbiana observada nas áreas referentes a Ss eSsV deveser reflexo de serem materiais provenientes de subsolo, enquanto as menores atividades nas áreas SS eAR (provenientes de camada superficial de solo) devem ser decorrentes da redução da população microbiana causada pelo processoe, ou, período de armazenamento ao ar livre. Williamson \& J ohnson (1990) concluíram que grande parte da biomassa na camada superficial de solo empilhado estava morta e que parte da microflora sobrevivente existia em formas inativas.

A atividade microbiana do solo de mata secundária com adição de carbono (C) ou carbono mais nitrogênio $(C+N)$, como na condição natural, permaneceu maior do que a dos demais sítios estudados. Na amostra de mata secundária, o fornecimento isol ado de carbono promoveu níveis de atividade microbiana similares àquel es obtidos com o fornecimento conjunto de carbono e nitrogênio (Figura 2), apesar da maior relação C/N (Quadro 1).
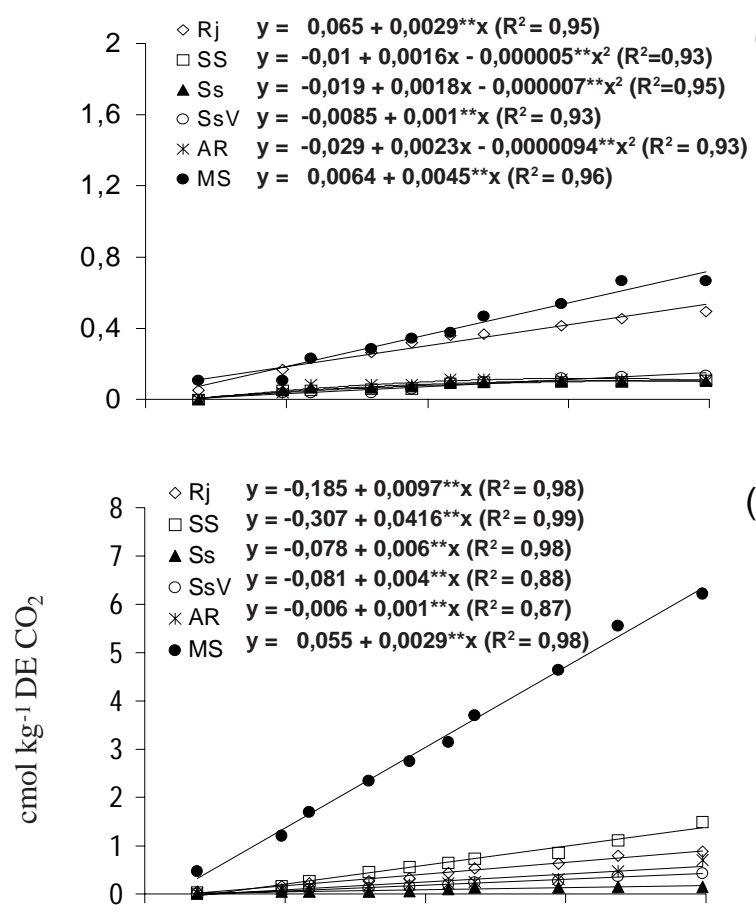

(b)

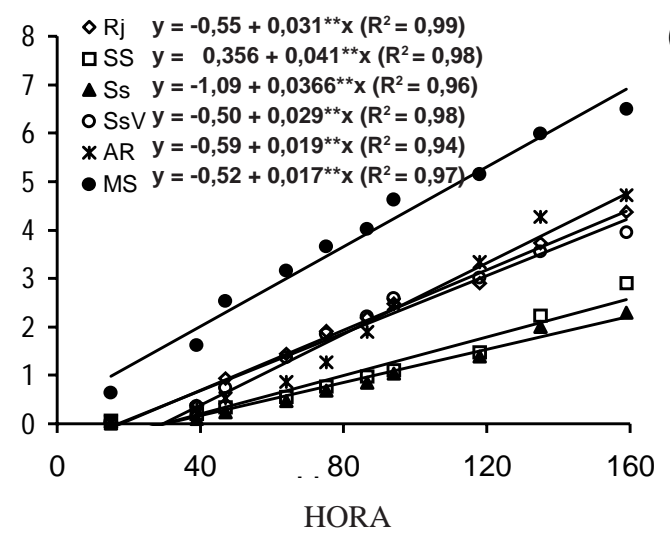

(c)

Figura 2. Respiração microbiana de diferentes substratos representantes de sítios de área de mineração de ferro, ao natural (a), com adição de sacarose (b) e de sacarose + uréia (c). [Rejeito de flotação (Rj); Solo Superficial (SS); Subsolo (Ss); Subsolo com Vegetação(SsV); Área em Revegetação (AR); Mata Secundária (MS)]. (** coeficientes significativos a $1 \%$, teste $t$ ). 
I sto mostra que, neste sítio, o carbono encontra-se em formas humificadas ou que a composição da serapilheira não é favorável à atuação dos microrganismos. Nos demais sítios, no entanto, a atividade microbiana respondeu mel hor à aplicação conjunta de carbono e nitrogênio, explicando-se pelos baixos teores desses nutrientes nas amostras, em relação à mata florestal. Esses resultados demonstram a importância da adição de fontes de carbono e nitrogênio nos sítios ou substratos a serem recuperados, visando à melhoria das condições bioquímicas, o que poderá favorecer a revegetação e retomada do equilíbrio antes presentes nessas áreas.

Mesmo com o fornecimento de carbono e nitrogênio, a atividade microbiana, medida pela respiração, nas áreas perturbadas não atingiu o mesmo patamar observado na área de mata secundária. Isto confirma o impacto exercido pela atividade de mineração sobre a população microbiana, bem como reforça a validade de utilização de métodos de avaliações bi ológi cas como indicadores de degradação e, ou, recuperação.

Considerando o grande volume de rejeito que é gerado pela atividade da mineração sendo a atividade microbiana indicadora de qualquer atividade que vise à sua incor poração como fonte de um novo ecossistema, deve-se basear, em princípio, no fornecimento de materiais orgânicos, que funcionem como fonte de $\mathrm{C}, \mathrm{N}$ e regulador do $\mathrm{pH}$. $\mathrm{Na}$ condição estudada, o fornecimento de $\mathrm{C}$ e $\mathrm{N}$ ao sistema também seria necessário para o melhor funcionamento da camada superficial de solo armazenada como substrato para a revegetação da área.

\section{CONCLUSÕES}

1. A atividade mineradora reduziu o teor de carbono, de nitrogênio, número de esporos de F MA, bem como a populaçãoe atividade de microrganismos do solo.

2. Nos materiais/substratos resultantes da atividade mineradora, houve necessidade de fornecimento de carbono e nitrogênio para retomada da atividade microbiana.

3. As avaliações microbiológicas do solo foram capazes de distinguir os estados de perturbação ou recuperação das diferentes áreas estudadas.

\section{AGRADE CIMENTOS}

À SAMITRI, S.A., Mariana (MG), peloapoio para a realização do trabalho, especialmente na pessoa do Pesquisador Rodrigo Dutra Amaral .

\section{LITE RATURA CITADA}

BARTH, R.C. Avaliação da recuperação de áreas mineradas no Brasil. Viçosa, Sociedade de Investigação Florestal, 1989. 41p. (Boletim técnico, 1)

BENTHAM, H.; HARRIS, J .A.; BIRCH, P.\& SHORT, K.C. Habitat classification and soil restoration assessment using analysis of soil microbiologicas and physi cochemical characteristics. J . App. Ecol., 29:711-718, 1992.

CATTELAN , A.J . \& VIDOR, C. Flutuações na biomassa, atividade e população microbiana do solo em função de variações ambientais. R. Bras. Ci. Solo, 14:133-142, 1990a.

CATTELAN, A.J . \& VIDOR, C. Sistemas deculturas ea população microbiana do solo. R. Bras. Ci. Solo, 14:125-132, 1990b.

EMPRESA BRASILEIRA DE PESQUISA AGROPECUÁRIA EMBRAPA. Levantamento e conservação de sol os. Manual de métodos de análises de solo. Rio de J aneiro, 1979. não paginado.

FOX, J .E.D. Rehabilitation of mined lands. For Abstr., 45:565595, 1984.

GERDEMANN, J.W. \& NICOLSON, J.H. Spores of mycorrhizal Endogone species estracted from soil by wet sieving and decanting. Trans. Br. Mycol. Soc., 46:235-244, 1963.

LAMONT, B.B. Biophysical constraints to the rehabilitation of mine wastes. In: FOX, J.E.D. ed. Rehabilitation of mined lands in western Australia. South Bentley, Western Australian Institute of Technology, 1978. p.37-45.

MOTTA NETO, J.A.; MORAES, A. \& LUCCHESI, L.A.C. Avaliação do uso de forrageiras e de adubações na recuperação de um solo degradado pela mineração de xistoI. Propriedades químicas. In: SIMPÓSIO SUL AMERICANO E SIMPÓSIO NACIONAL DE RECUPERAÇÃO DE ÁREAS DEGRADADAS, 1 e 2, Foz do I guaçu. 1994. Anais. Curitiba, Fundação de Pesquisas Florestais do Paraná - FUPEP, 1994. p.257-265.

RICHES, J .R.H. \& J ONES, H. Arid area mine Mt. Whalebachk, Western Australia. J . Soil Water Conserv., 35:223-229, 1979.

RIVES, C.S.; BAJ WA, M.I.; LIBERTA, A.E. \& MILLER, R.M. Effects of topsoil storage during surface mining on the viability of vesicular-arbuscular mycorrhiza. Soil Sci., 129:253-257, 1980.

SIQUEIRA, J .O.; MOREIRA, F.M.S.; GRISI, B.M.; HUNGRIA, M. \& ARAUJ O, R.S. Microrganismos e processos biológicos no sol o: perspectiva ambiental, Brasília, Empresa Brasileira de Pesquisa Agropecuária, 1994. 142p.

STROO, H.F. \& J ENCKS, E.M. Enyme activity and respiration in minesoils. Soil Sci. Soc. Am. J ., 46:548-553, 1982.

WILLIAMSON, J.C. \& J OHNSON, D.B. Determination of the activity of soil microbial populations in stored and restored soils at opencast coal sites. Soil Biol. Biochem., 22:671-675, 1990.

WOLLUM II, A.G. Cultural methods for soil microorganisms. In: MILLER, R.H. \& KEENEY, D.R., eds. Methods of soil analysis: chemical and microbiological properties. Madison, Soil Science Society of America, 1982. p.781-802. 